\title{
Análise foucaultiana de vídeos educativos para as Ciências da Saúde: ensaindo uma metodologia"
}

Marcia Bastos de Sá

Vera Helena Ferraz de Siqueira²

\section{Introdução}

A incorporação da imagem em movimento a situações de ensino e aprendizagem teve início nas primeiras décadas do século $X X$, e hoje, no Brasil, inúmeros são os espaços - escolas, postos de saúde, hospitais, dentre outros que contam com, pelo menos, uma televisão e equipamento para reprodução de audiovisuais. A presença desses suportes nesses ambientes pode ser entendida como o reconhecimento do valor da imagem em movimento em/ou para ações pedagógicas, o que justifica a crescente importância dos estudos que se voltam à compreensão de aspectos relacionados a essa temática. Nesse sentido, nota-se recentemente, por exemplo, o aumento considerável de artigos e publicações dedicados às relações entre educação e cinema ou educação e televisão.

Também vem despertando o interesse de pesquisadores o vídeo educativo, entendido por Xavier (2008, p.15) como uma produção que, estruturada como um ato comunicativo, tende a apresentar, "de um modo ou de outro, uma demarcação, uma metodologia de ensino, um princípio pedagógico, voltados para um domínio específico de conhecimento ou para o adestramento de uma prática". Contudo, é digno de atenção o fato de que o estudo do vídeo educativo em si mesmo, como a modalidade de produção audiovisual mais explicitamente vinculada às intenções pedagógicas, não seja o foco preferencial das investigações. Em levantamento da produção intelectual no Portal CAPES, utilizando os termos "vídeo" e "educação", observamos que a maioria das 20 teses de doutorado defendidas sobre a temática entre 1999 e 2007 se refere ao uso do vídeo como ferramenta em pesquisas ou a estudos de recepção.

A pesquisa que fornece subsídios para o presente artigo investiga o acervo de vídeos educativos do Laboratório de Vídeo Educativo do Núcleo de Tecnologia Educacional para a Saúde, ${ }^{3}$ buscando analisar deslocamentos nas práticas discursivas e não discursivas sobre educação e saúde nas três últimas décadas.

Os centros de produção de vídeos nas universidades brasileiras surgiram a partir da década de 1970, tendo sido o LVE/NUTES o mais antigo entre eles, e o único com concentração preferencial sobre a área das Ciências da Saúde até o final dos anos 1980 (Bortoliero, 2002). Dos 219 títulos produzidos entre 1975 e 2008, a maior parte é dedicada à circulação de conhecimentos, práticas

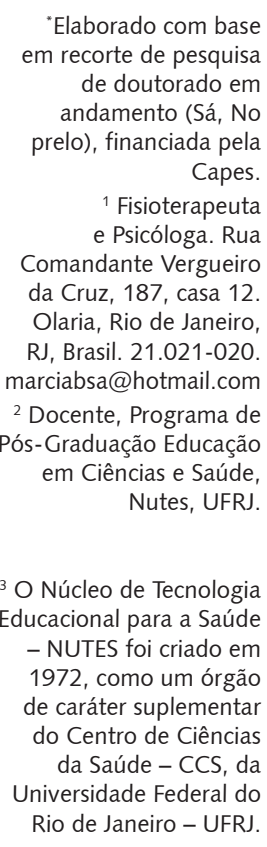


e propostas de reflexão referidos ao ensino biomédico e ao campo da saúde, e, paralelamente a estes, realizam-se avaliações e reflexões críticas de pesquisadores sobre o material produzido e sobre os processos de produção desenvolvidos (Rezende, Struchiner, 2009; Siqueira, 2006, 1998).

Qualquer filme e, portanto, também os vídeos educativos elaboram e fazem circular discursos, produzindo sistemas de significação. Segundo Aumont e Marie (2003, p.82), por exemplo, o estudo desses sistemas de significação desenvolvem-se em quatro grandes vertentes: pela semiologia do filme, tomando o "discurso fílmico" como objeto de estudo; pela pragmática, analisando "os diversos atos que um discurso realiza, as relações entre o locutor e o receptor"; pela teoria psicanalítica e pela sociologia, analisando "toda produção discursiva pelo inconsciente e pela ideologia"; pela "linguística do filme, de inspiração generativa, que entende a teoria do discurso como teoria da determinação histórica dos processos semânticos".

Contudo, pensar em discurso e, muito especialmente, na análise de discursos, nos remete também a Michel Foucault. Suas formulações sobre esse tema foram elaboradas numa rede de tensões que incluía debates com a gramática, a linguística e a semiologia, pois a intenção era

não mais tratar os discursos como conjuntos de signos (elementos significantes que remetem a conteúdos e representações), mas como práticas que formam sistematicamente os objetos de que falam. Certamente os discursos são feitos de signos; mas o que fazem é mais que utilizar esses signos para designar coisas. É esse mais que os torna irredutíveis à língua e ao ato da fala. É esse "mais" que é preciso fazer aparecer e que é preciso descrever. (Foucault, 2005b, p.55)

Esse "mais" de que fala Foucault é definido como enunciado - "uma função que cruza um domínio de estruturas e unidades possíveis e que faz com que [estas] apareçam, com conteúdos concretos, no tempo e no espaço" (Foucault, 2005a, p.98) - e é sobre ele que se edifica sua teoria do discurso. Resumidamente, pode-se dizer que, para o autor, o discurso é "um conjunto de enunciados que podem pertencer a campos de conhecimento diferentes" (o jurídico, a economia, a política etc), "mas que obedecem a regras de funcionamento comuns" que, por sua vez, "reproduzem um certo número de rupturas historicamente determinadas" (Revel, 2005, p.37).

Ao assistirmos os vídeos educativos que compõem o acervo sobre o qual nos debruçamos, inquietou-nos a impressão de que aqueles materiais diziam e mostravam mais do que aquilo que intencionalmente eles pretendiam dizer e mostrar. Junto com os conteúdos, as formas, as representações, os contextos, algo "ao mesmo tempo não visível e não oculto" parecia anunciar sua presença, deixar um vestígio. Como ter acesso a isso? Como entender, como analisar isso que parece querer escapar dentro da cadeia de elementos que formam uma produção audiovisual?

Essas questões acabaram por nos levar à pesquisa de doutorado em andamento ${ }^{4}$, da qual este trabalho é um recorte. No presente texto, delineamos breve exercício de caráter exploratório que, partindo das noções de acontecimento e arquivo como âncoras teóricas, seleciona e analisa dois vídeos "Coração: relações e morfologia externa" (1977) e "Hipotireoidismo na infância" (1976) - visando indicar possíveis contribuições do referencial foucaultiano para a análise de materiais audiovisuais.

\footnotetext{
${ }^{4}$ Pesquisa de doutorado intitulada "Entre o governo de si e o governo dos outros: uma análise foucaultiana da liberdade e suas práticas em vídeos educativos do Nutes/UFRJ" (bolsa Capes).
} 


\section{Acontecimento e arquivo}

De acordo com Revel (2005, p.13), Foucault propõe duas compreensões distintas para a noção de acontecimento: a primeira toma o acontecimento como um fato que trabalhado pelo método arqueológico possibilitará a reconstrução de "toda uma rede de discursos, de poderes, de estratégias e de práticas"; a segunda, alinhada à compreensão "do discurso como uma série de acontecimentos," concebe acontecimento como "uma cristalização de determinações históricas," implicando a "análise de diferentes redes e níveis aos quais os acontecimentos pertencem" com vistas a uma investigação "da relação entre os 'acontecimentos discursivos' e os acontecimentos de outra natureza (econômicos, sociais, políticos, institucionais)".

Foucault explica que a inserção do acontecimento no centro das suas análises e, mais especificamente, a concepção do "discurso como uma série de acontecimentos", o situa "automaticamente na dimensão da história" (Foucault, 2006a, p.256). Visando distinguir sua noção da ideia de "história acontecimental", própria do campo da História tradicional, o autor cunha o termo 'acontecimentalização' como "a tomada de consciência das rupturas da evidência induzidas por certos fatos" ou "a irrupção de uma singularidade histórica" (Revel, 2005, p.14). A partir desta especificação, dois discursos foram desenvolvidos: um primeiro, consistindo em dizer que repetimos alguns acontecimentos sem perceber, dirige o foco de atenção para as permanências, ou seja, para os discursos, práticas, comportamentos e instituições que inelutavelmente nos atravessam na história do presente; o segundo, visando buscar na atualidade "os traços de uma ruptura acontecimental", privilegia uma identificação das possibilidades de mudança que emergem "da contingência histórica, que nos faz ser o que somos" (Revel, 2005, p.14-21).

Existem, portanto, acontecimentos de diferentes níveis - fatos ordinários, que se repetem e parecem comuns, ou eventos extraordinários, inesperados, que promovem rupturas. Seja pela repetição ou pela excentricidade, os acontecimentos discursivos e não discursivos (as práticas) estão sempre carregados de marcas, de registros, que apontam para uma historicidade onde eventos de várias naturezas (político, econômico etc.) e temporalidades (presente e passado) mantêm relações se justapõem, sobrepõem, interpelam, atualizam e coexistem. Para Foucault (2008, p.5), é importante considerar "que existe um escalonamento de tipos de acontecimentos diferentes que não têm o mesmo alcance, a mesma amplitude cronológica, nem a mesma capacidade de produzir efeitos" e que, exatamente por isso, "o problema é ao mesmo tempo distinguir acontecimentos, diferenciar as redes e os níveis a que pertencem e reconstituir os fios que os ligam e que fazem com que se engendrem, uns a partir dos outros".

Para dar conta do estudo do acontecimento, Foucault desenvolve a arqueologia, um "[...] tipo de pesquisa que se dedica a extrair os acontecimentos discursivos como se eles estivessem registrados em um arquivo", procurando "reconstituir um campo histórico em sua totalidade, em todas as suas dimensões políticas, econômicas", pois o problema do autor era "encontrar a matéria que convém analisar, o que constituiu o próprio fato do discurso. [...] descobrir por que e como se estabelecem relações entre os acontecimentos discursivos" (Foucault, 2006a, p.257-258).

$\mathrm{O}$ arquivo foucaultiano, contudo, não corresponde à soma de todos os textos conservados por uma civilização, nem às instituições que protegem seu armazenamento e acesso. Em "A arqueologia do saber" todo um capítulo é dedicado à descrição e ao estudo das relações entre o enunciado e o arquivo, e nele o arquivo é explicitado como

[...] a lei do que pode ser dito, o sistema que rege o aparecimento dos enunciados como acontecimentos singulares. [...]. O arquivo [...] é o que, na própria raiz do enunciadoacontecimento e no corpo em que se dá, define, desde o início, o sistema de sua enunciabilidade. (Foucault, 2005a, p.147)

A noção de arquivo, em suma, se refere ao sistema geral de formação e transformação dos enunciados, ou seja, ao sistema das condições históricas de possibilidade dos enunciados, ou, ainda, ao "conjunto dos discursos efetivamente pronunciados", considerando-se esse conjunto 
não somente como um conjunto de acontecimentos que teria, ocorrido uma vez por todas e que permaneceriam em suspenso, nos limbos ou no purgatório da história, mas também como um conjunto que continua a funcionar, a se transformar através da história, possibilitando o surgimento de outros discursos. (Foucault, 2005b, p.145)

Pode-se perceber que as expressões arquivo, acontecimento e enunciado encontram-se irremediavelmente ligadas, ocupando a primeira delas o lugar de conceito-mestre na arqueologia.

A seguir, são analisados os vídeos citados anteriormente. No primeiro, trabalhamos sobre uma cena entendendo-a como um acontecimento ordinário, familiar, que evidencia uma permanência que será apreciada em nossa análise. No outro, evento imprevisto ocorrido durante o processo de produção do vídeo possibilitou análise sobre a noção de acontecimento como possibilidade de mudança e um aprofundamento a respeito do significado do arquivo como "a lei do que pode ser dito" (Foucault, 2005b, p.147).

\section{“Coração: relações e morfologia externa" (1977)}

Este vídeo é dedicado ao estudo morfológico do coração e de suas relações com outros órgãos do tórax. Sua duração é de quarenta minutos e o apresentador aparece em cena por apenas seis minutos ao longo de todo o filme. Sempre presentes, contudo, são sua voz e a imagem dos recursos utilizados para ilustrar as descrições, denominados no vídeo como "modelos" - vivo, plástico, cadáver de criança, RX, peça anatômica. A escolha por cada um desses "modelos" parece estar apenas relacionada à sua adequação para ilustrar o conteúdo descrito.

Selecionamos, deste vídeo, um recorte de 1 minuto e 6 segundos para análise. A cena é composta por um take ${ }^{5}$, com um único plano estático, com enquadramento ${ }^{6}$ frontal, dirigido dos pés para a cabeça, ligeiramente em plongée, ${ }^{7}$ mostrando o terço superior (tórax, ombros e cabeça) do cadáver de uma criança. Um pequeno bastão interfere intermitentemente no quadro em consonância com texto proferido por uma voz off', ora localizando ou deslocando, no cadáver, os elementos sobre os quais fala o narrador, ora apenas acompanhando seus movimentos expressivos. Pode-se observar o deslocamento de sua sombra sobre o quadro, sendo o texto proferido composto por sete frases curtas que explicam ou justificam o que foi feito, localizando os elementos no tórax.
5 Tomada: começa no momento em que se liga a câmera até quando é desligada.

${ }^{6}$ São os limites laterais, superior e inferior da cena filmada. É a imagem que aparece no visor da câmera.

${ }^{7}$ Câmera focalizando a pessoa ou o objeto de cima para baixo; também chamado ângulo alto. ${ }^{8}$ Uma voz de alguém que está presente, mas não aparece na cena. 


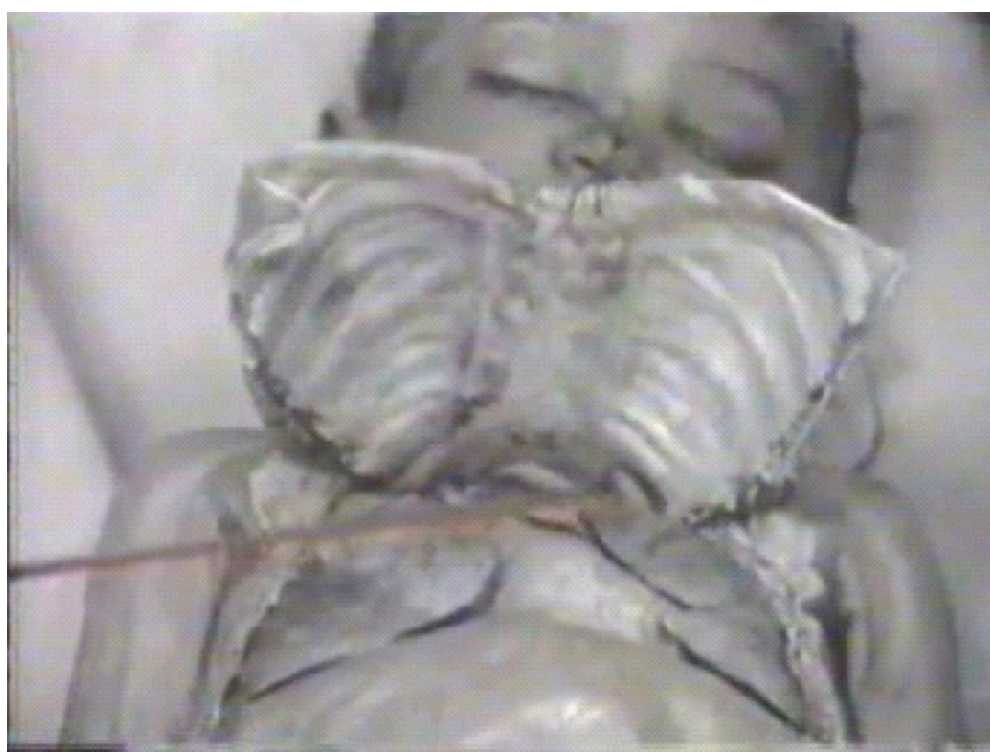

A imagem do cadáver da criança nos remeteu, imediatamente, a um detalhe da pintura "Aula de anatomia do Dr. Joan Deyman", de Rembrandt, de 1656.

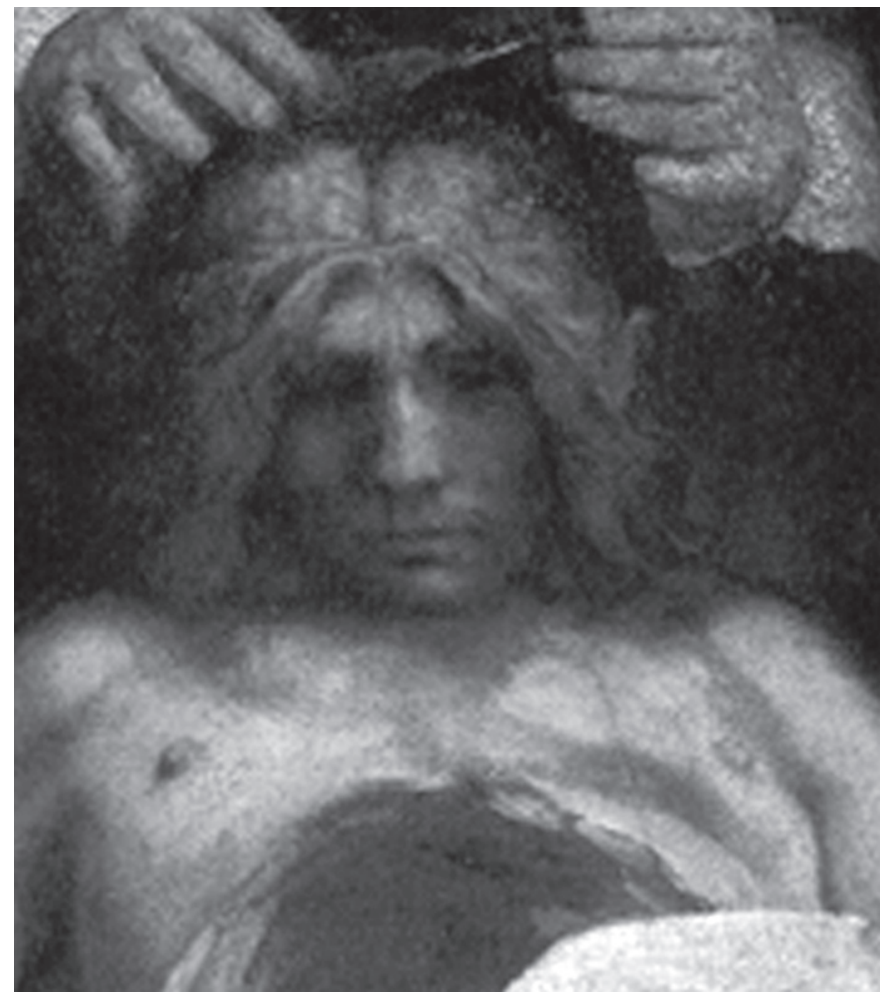

Figura 2. Detalhe da pintura de Rembrandt 


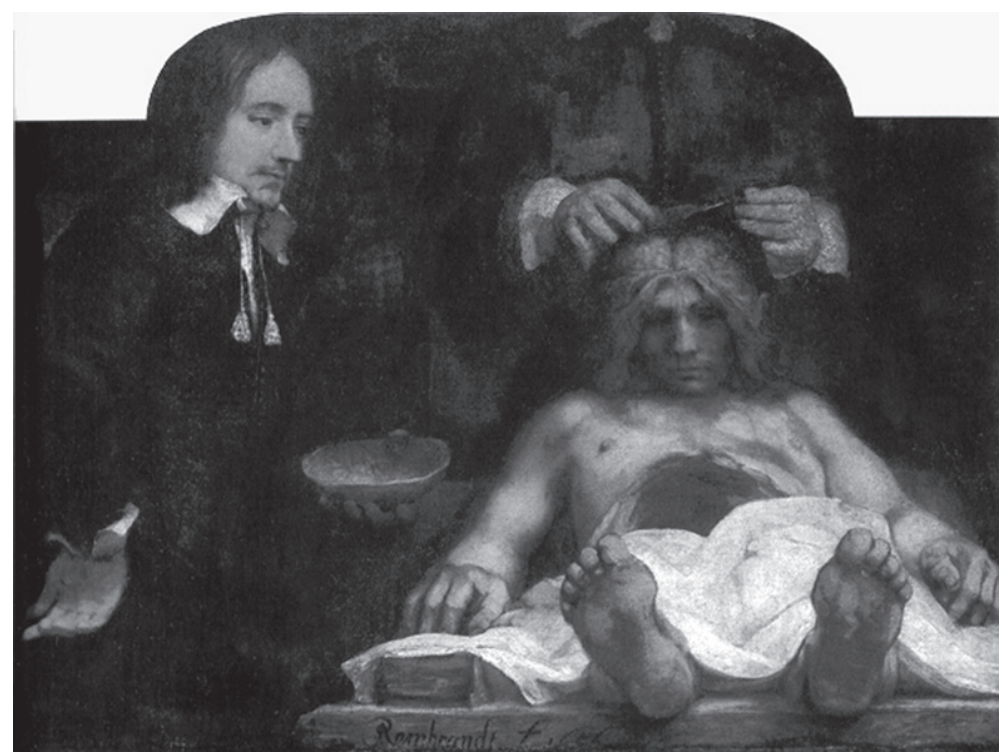

Figura 3. "Aula de anatomia do Dr. Joan Deyman"

O que faz com que uma pintura de 1656 seja evocada e, de certo modo, repetida numa imagem de 1977 ? O que permite que uma certa prática - a prática do ensino de anatomia - seja representada de modo tão semelhante (embora em materialidades diferentes) apesar dos mais de 300 anos que separam a produção do quadro da produção do vídeo?

A análise do recorte selecionado, entendido como evidência de um acontecimento no sentido ordinário, ou seja, como algo que, pela repetição, permanece distinguindo o discurso médico até os dias de hoje, poderá ser útil para entendermos algo sobre as "relações complexas e embaralhadas" que existem entre imagens e palavras (Foucault, 2005c, p.79-80), e, muito especialmente, como enunciados e visibilidades as habitam.

Seguindo a sugestão deleuziana, "rachamos"10 (Deleuze, 2006, p.6062) a única imagem deste frame para buscar o que mais poderia estar sendo mostrado - as visibilidades - e dito - os enunciados - e que não nos é dado a "ver" e "ouvir" diretamente. A mão segurando a varinha, a sombra ocasional e a voz daquele que, no recorte, conduz uma prática de ensino não apontam para um sujeito específico, mas para uma vacância - a um só tempo oferta (convite), promessa e condição - de uma posição de sujeito dentro da ordem de um discurso, neste caso, o discurso médico. A oferta para que um indivíduo ocupe a função de representante do saber médico inclui uma promessa de poder que, no entanto, para ser alcançada, impõe a aceitação e submissão às regras e procedimentos que produzem e regulam tanto o discurso médico e seu saberpoder quanto seus representantes. A este respeito, Foucault escreve: "Nisto não há nada de espantoso, visto que o discurso [...] não é simplesmente aquilo que traduz as lutas ou os sistemas de dominação, mas aquilo por que, pelo que se luta, o poder do qual queremos nos apoderar" (1999, p.10).

Ao refletir sobre os procedimentos de controle e delimitação do discurso, Foucault (1999, p.19) chama nossa atenção para a "vontade de verdade", segundo ele, a menos falada e a mais "prodigiosa maquinaria" dos "sistemas de exclusão que atingem o discurso". Entendida de modo simples como o conjunto de operações destinadas à separação do verdadeiro e do falso, essa "vontade de verdade" pressiona nossos modos de conhecer, saber e ser. Assim, o uso do

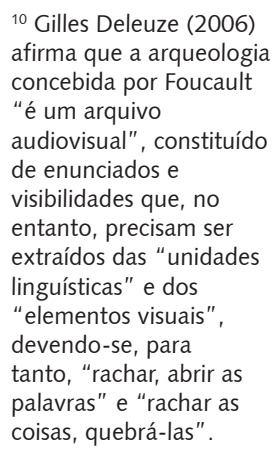
afirma que a arqueologia concebida por Foucault "é um arquivo audiovisual", constituído de enunciados e visibilidades que, no entanto, precisam ser extraídos das "unidades linguísticas" e dos "elementos visuais", devendo-se, para tanto, "rachar, abrir as palavras" e "rachar as coisas, quebrá-las". 
${ }^{11}$ Para o aprofundamento desse tema, sugerimos consulta ao livro "O nascimento da clínica", escrito por Foucault em 1963.

12 Informação fornecida pela equipe técnica do Laboratório de Vídeo Educativo do NUTES/ UFRJ, responsável pelas produções. cadáver como recurso ilustrativo, a evocação da pintura de Rembrandt, o uso do bastão para assinalar elementos no cadáver, o anonimato do sujeito no quadro, a voz off que enuncia os ensinamentos, as frases curtas, a íntima relação entre o que se fala e o que se mostra ${ }^{11}$, destinam-se à delimitação e controle do saber e dos sujeitos que produzem e são produzidos pelo discurso médico.

Procuramos evidenciar que, no recorte analisado, se desenrolaram dois níveis de texto: um primeiro, imediatamente apreensível, ensina a localização do coração e suas relações morfológicas com outros elementos do tórax utilizando um cadáver como modelo ilustrativo; um segundo texto, da ordem dos enunciados e das visibilidades, se desenvolve "mascarado", destinado a produzir algo mais complexo, a saber, a permanente produção do discurso médico como um "discurso de verdade". E, mais uma vez, nos remetendo a Foucault:

[...] na vontade de dizer esse discurso verdadeiro, o que está em jogo, senão o desejo e o poder? [...] a vontade de verdade, essa que se impõe a nós há bastante tempo, é tal que a verdade que ela quer não pode deixar de mascará-la. (Foucault, 1999, p.20)

\section{“Hipotireoidismo na infância" (1976)}

Esse vídeo, elaborado para abordar "o hipotireoidismo congênito, incluindo desde os sinais clínicos decorrentes da insuficiência tireoidiana, o diagnóstico diferencial através dos exames complementares, até a terapêutica apropriada" (UFRJ/NUTES, 1997, p.69), possui duas edições. A primeira, com 22 minutos de duração, corresponde ao previsto no roteiro original12: exposição didática sobre o tema, utilizando, como recursos de apoio, textos escritos e gráficos (imagem 4); exame físico de paciente portador de hipotireoidismo congênito e exposição comparativa das características deste em relação às de uma menina da mesma idade sem hipotireoidismo (imagem 5); consulta subsequente à alta hospitalar, visando ilustrar os efeitos da terapêutica.

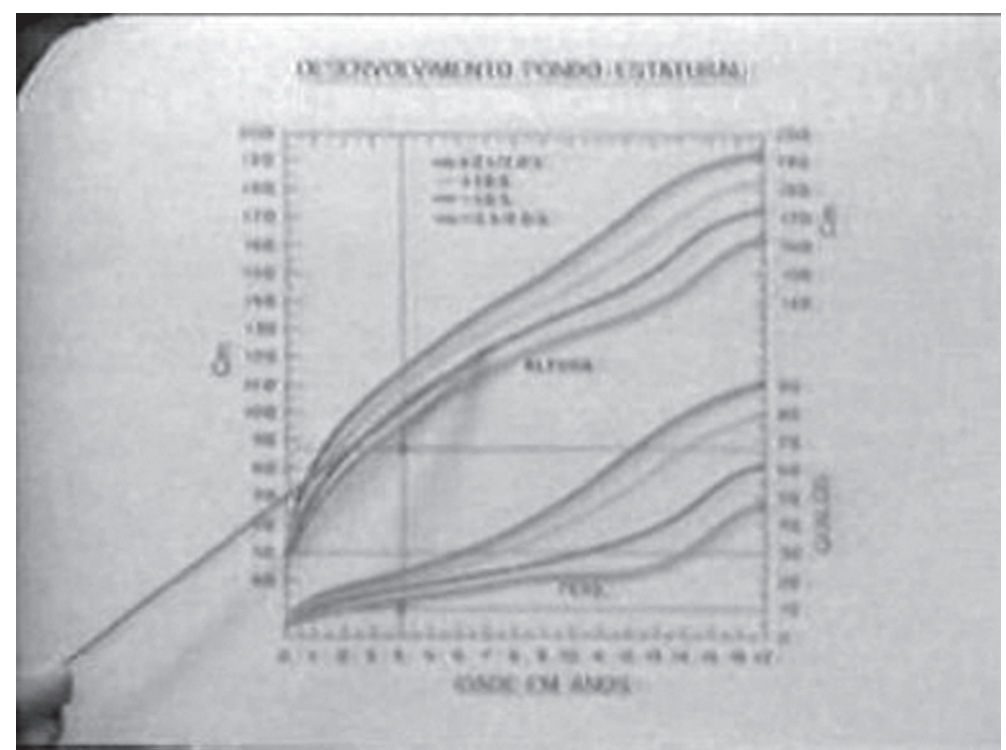

Figura 4. Gráfico apresentado no vídeo "Hipotireoidismo na infância". Texto em off que acompanha a imagem: "Esta é a curva de crescimento dos meninos normais. Ela mostra não só a estatura média para cada idade como também as variações normais de estatura para uma determinada idade" 


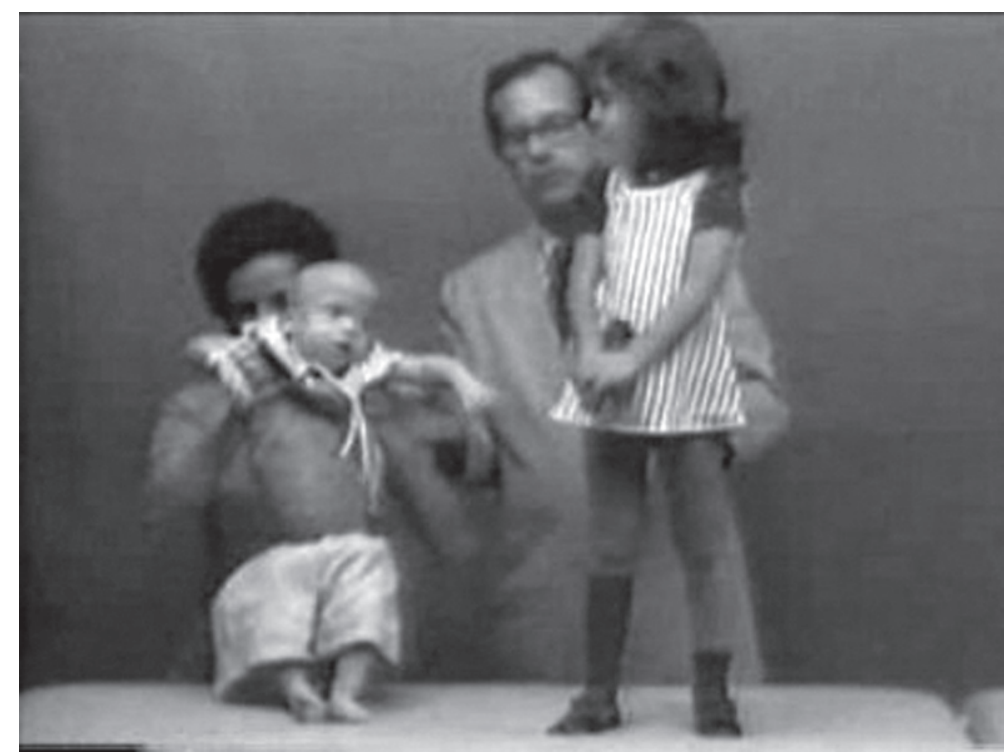

Figura 5. Frame do mesmo vídeo, mostrando diferenças entre crianças com e sem Hipotireoidismo congênito. Texto que acompanha a imagem: "A diferença estatural demonstra a importância dos hormônios tireoidianos para o crescimento adequado"

Essa primeira edição utiliza o mesmo padrão observado no vídeo "Coração: morfologia e relações externas": o texto do filme também é composto por frases curtas e objetivas, utilizando-se recursos visuais - imagens de gráficos e tabelas, "modelos" vivos, imagens radiológicas - e demonstrações de exame, como suporte ou ilustração para o que é dito.

A segunda edição do vídeo "Hipotireoidismo na infância", no entanto, acrescenta, ao roteiro original, sequências filmadas em decorrência de evento inesperado ocorrido durante o tratamento - o não-comparecimento do paciente Carlos Alberto ${ }^{13}$ à primeira consulta ambulatorial, trinta dias após a alta hospitalar. Essas sequências apresentam: entrevista concedida pela médica assistente, Dra. Maria Helena, ao médico responsável, Dr. Solberg ${ }^{14}$, sobre visita realizada à família do menino; depoimento do Dr. Solberg sobre os fatores que determinaram a ausência da criança; conversa em off entre a Dra. Maria Helena e a mãe de Carlos Alberto, "coberta" por imagens filmadas do local de sua residência.

A falta do paciente à consulta interrompeu abruptamente não apenas o processo terapêutico, mas também o de produção do vídeo. O imperativo da retomada de ambos mobilizou a confluência dos diferentes olhares e saberes dos profissionais envolvidos na situação - médicos, assistente social e equipe responsável pela produção do vídeo - resultando na busca da criança em sua residência. Essa decisão provocou tanto uma reflexão do médico-professor em relação ao conhecimento e às práticas médicas vigentes sobre o hipotireoidismo congênito, explicitada mais adiante, como uma re-invenção do vídeo original, agregando uma dimensão documentária ao formato tradicional característico do vídeo educativo praticado pelo Nutes, nesse período ${ }^{15}$.

A consulta de follow-up e a conclusão da filmagem do vídeo ocorreram com um atraso de dois meses e meio em relação ao previsto. A visita domiciliar ao paciente e a consequente inclusão de informações sobre as condições socioeconômicas da família, na cena clínica, possibilitaram: o retorno de Carlos

\author{
${ }^{13}$ Utilizamos os mesmos \\ nomes referidos no \\ vídeo. Os requisitos \\ relativos à obtenção \\ de autorização para \\ uso de imagem, som \\ e identificação foram \\ atendidos na fase de \\ produção do mesmo. \\ ${ }^{14} \mathrm{~A}$ autoria desse vídeo \\ é creditada a Pedro \\ Ribeiro Collet-Solberg - \\ Solberg, P. no Catálogo \\ de Vídeos Educativos \\ do LVE - pediatra, \\ professor na Faculdade \\ de Medicina da UFRJ à \\ época da produção do \\ vídeo, considerado, hoje, \\ um dos pioneiros da \\ Endocrinologia Pediátrica \\ no Brasil. A este respeito, \\ ver "Jornal da Assex", \\ dez. 2006, ano 13, p.06. \\ Disponível em: <http:// \\ www.assex.org.br/jornal/ \\ arquivo/jassex52.pdf $>$. \\ Acesso em: 14 jan. 2011. \\ 15 Sobre o assunto, ver \\ referências: Rezende \\ e Struchiner, 2009 \\ Siqueira, 1998 e 2006.
}


Alberto à instituição e ao tratamento, uma ressignificação, pela equipe, sobre o seu não-comparecimento à consulta agendada, e uma reconsideração a respeito do que também deveria ser levado em conta no diagnóstico e tratamento do hipotireoidismo congênito.

Tomando por base as sequências gravadas no local de residência do paciente e as informações relatadas pela médica que realizou a visita, o médico - e professor - tece, em depoimento incluído no terço final do vídeo, considerações a respeito de aspectos que não devem ser negligenciados no entendimento e no tratamento do hipotireoidismo congênito:

No primeiro exame físico feito em Carlos Alberto eu declarei que todos os fatores fundamentais para o crescimento e o desenvolvimento normal tinham estado presentes com exceção de um, a função tireoidiana. Quando Carlos Alberto faltou à primeira visita marcada no ambulatório, nós fomos obrigados a ir procurá-lo no ambiente em que vivia e tomamos consciência de que Carlos Alberto não é simplesmente um caso de hipotireoidismo congênito, mas uma criança que, como nós veremos, vive num ambiente de extrema miséria, e esta miséria e a desnutrição daí resultantes podem afetar o crescimento e o desenvolvimento de uma criança quase tanto quanto uma deficiência hormonal. Além disso, a dificuldade na aquisição de remédios pode alterar inteiramente o plano terapêutico previsto. No tratamento de Carlos Alberto nós teremos que levar em consideração toda a condição sócio-econômica da família, e tratar não um caso isolado de uma doença, como a gente tende a simplificar, mas um ser humano, uma criança, vivendo em condições extremamente difíceis; vivendo e indo voltar para esse ambiente, uma vez saída do hospital. O verdadeiro sucesso terapêutico só será obtido se todos esses dados forem levados em consideração.

O que o médico pôde refletir a partir da busca da criança, e que, como professor, procura ensinar com seu depoimento, aponta para o tema da triagem neonatal de erros inatos do metabolismo, dentre os quais se inclui o hipotireoidismo congênito, que passou a ocupar o cenário médico mundial em 1961, quando, nos Estados Unidos, foi iniciada a triagem para a fenilcetonúria.

Em 1976 - ano de produção do vídeo - foi implantado, também nos Estados Unidos, o primeiro Programa Piloto de Triagem Neonatal para hipotireoidismo congênito, enquanto, no Brasil, pioneiramente, ainda se estabelecia o primeiro projeto de triagem neonatal para fenilcetonúria. A testagem para hipotireoidismo congênito no Brasil foi iniciada em 1986 - dez anos após a produção do vídeo, portanto - e, somente em junho de 2001, o Ministério da Saúde publicou a Portaria GM/MS n 822, criando o Programa Nacional de Triagem Neonatal (PNTN), com a participação de todos os Estados brasileiros que, representados pelos Serviços de Referência em Triagem Neonatal (SRTN) credenciados, se organizariam sob os mesmos princípios e procedimentos: uma estrutura de diagnóstico, busca ativa, tratamento e acompanhamento das doenças triadas, pagas com recursos do SUS destinados para este fim ${ }^{15}$.

A análise desse vídeo favorece a compreensão do significado do arquivo

${ }^{15}$ As informações sobre a triagem de erros inatos do metabolismo estão disponíveis em: <http:// www.sbtn.org.br/ pg_soc_historico.htm > e $<$ http://www.unisert.org. br/historia.htm $>$. Acessos em: 14 jan. 2011. como "a lei do que pode ser dito" por possibilitar uma apreciação a respeito das tensões entre os vários níveis de relações de saber-poder, e destas sobre escolhas, decisões e práticas, aparentemente individuais. Para Foucault, toda e qualquer relação social ou institucional e, portanto, todos os discursos e 
práticas são produzidos dentro de relações de saber-poder que, por sua vez, "são relações móveis, isto é, podem se modificar, não são dadas de uma vez por todas". Isto, por sua vez, implica admitir - excetuando-se as relações em que um dos polos pode "exercer uma violência infinita e ilimitada" sobre o outro - que, "para que se exerça uma relação de poder, é preciso que haja sempre, dos dois lados, pelo menos uma certa forma de liberdade" e, com ela, sempre a possibilidade de resistência e de produção de singularidades (Foucault, 2006b, p.276-277).

A decisão do médico em compartilhar suas ponderações sobre a prática clínica vigente, e sobre a sua própria prática, é importante por abrir um campo de reflexão a respeito de práticas individuais e coletivas marcadas pelo exercício da liberdade, isto é, de práticas claramente definidas a partir da escolha de uma determinada conduta dentre várias outras possíveis. Contudo, a liberdade, para Foucault, não corresponde à mera escolha entre alternativas distintas, mas ao desenvolvimento de práticas criativas, não usuais, que levem os sujeitos a um permanente processo reflexivo sobre si mesmos - prática ética - e sobre o mundo - prática política -, culminando na possibilidade de produção de novas formas de subjetividade capazes de resistir às práticas político-discursivas vigentes, e quiçá, transformá-las.

Assim, embora a prática da busca ativa faça parte da coleção de estratégias biopolíticas destinadas à gestão da vida humana, não consideramos a situação de busca do menino Carlos Alberto como uma mera reprodução destas: foi a busca daquela criança, naquela situação, que possibilitou um exercício crítico-reflexivo de todos os envolvidos na produção do vídeo, em face da diferença introduzida nas práticas que caracterizavam a clínica relativa ao tratamento do hipotireoidismo congênito e ao vídeo educativo, naquele momento.

Tomamos, como evidência do caráter coletivo dessa produção audiovisual, e de todas as decisões que permearam o processo, a passagem do uso da primeira pessoa do singular (eu) para a primeira pessoa do plural (nós) no depoimento do médico, sinalizando a autoria compartilhada das práticas que consideramos inovadoras, diante do desafio colocado por uma situação não prevista.

De acordo com o exposto, nos parece que o arquivo, longe de ser uma armadura que constrange a análise de mudanças das relações de força nas "malhas do poder", pode ser entendido como o ponto privilegiado de passagem da análise do saber à do poder, e desta à do sujeito; ou, dito de outro modo, do acesso da arqueologia à genealogia e, desta, à ética, pois, de fato, essas dimensões de análise se encontram imbricadas no projeto foucaultiano.

Se no arquivo podemos encontrar evidências das mais arraigadas forças de permanência - como as técnicas disciplinares, as práticas de normalização e a "vontade de verdade" -, podemos, também, encontrar os vestígios de mudanças experimentadas por sujeitos ou grupos de sujeitos, mesmo que, a princípio, não pareçam valiosos por emergirem de contingências circunscritas a uma situação específica e pontual, e não tenham sido capazes de instituir, de uma vez por todas, uma ruptura vultosa.

\section{Conclusão}

Partindo das noções de acontecimento e arquivo, selecionamos e analisamos dois vídeos educativos do acervo do NUTES/UFRJ. No primeiro, "Coração: morfologia e relações externas" (1977), partindo de um pequeno extrato do vídeo, composto por uma única imagem e por sete frases curtas e objetivas ditas em off, dirigimos nossa atenção para alguns aspectos concernentes à íntima relação, que ainda permanece, entre uma determinada forma de mostrar (ver) e de dizer (ouvir) na ordem do discurso médico.

No segundo vídeo, "Hipotireoidismo na infância" (1976), embora a permanência destacada no vídeo anterior - a relação entre mostrar/ver-dizer/ouvir - esteja presente, interessou-nos analisar os efeitos decorrentes de evento inesperado que interferiu no processo de produção do vídeo, efeitos esses entendidos como acontecimentos de ruptura porque concretizaram práticas alternativas, até então não habituais, tanto em relação ao tratamento de uma criança - daquela criança - com hipotireoidismo congênito, como em relação às práticas que estabeleciam o formato do vídeo educativo.

Cabe ressaltar que as análises não foram desenvolvidas da mesma maneira, porque os vídeos foram selecionados de modo a propiciarem - tal como sinalizado acima - discussões a respeito de acontecimentos de diferentes níveis, exigindo, portanto, diferentes formas de abordagem. 
A análise desses materiais nos levou a um deslocamento ao longo do projeto foucaultiano, de onde pudemos revê-los, especialmente o "Hipotireoidismo na infância", tendo em mãos elementos que trouxeram pistas para a investigação de como os indivíduos, exercitando sua liberdade, podem se constituir como sujeitos políticos e éticos, na fronteira dos campos altamente disciplinares e normalizadores da educação e da saúde.

Com as análises, a impressão de que os vídeos diziam e mostravam mais do que aquilo que intencionalmente eles pretendiam dizer e mostrar corresponde, agora, à compreensão de que esse tipo de material veicula um amálgama de performances discursivas e não discursivas - grosso modo, práticas sociais - que pode, e deve, ser investigado e analisado em três perspectivas complementares: a análise dos saberes, das relações de poder entre indivíduos e instituições, e das relações do indivíduo consigo mesmo.

\section{Colaboradores}

Marcia Bastos de Sá responsabilizou-se pela produção do manuscrito; Vera Helena Ferraz de Siqueira responsabilizou-se pela orientação e revisão do mesmo.

\section{Referências}

AUMONT, J.; MARIE, M. Dicionário teórico e crítico de cinema. Campinas: Papirus, 2003.

BORTOLIERO, S. A produção de vídeos educacionais e científicos nas universidades brasileiras: a experiência do Centro de Comunicação da Universidade Estadual de Campinas (1974-1989). In: CONGRESSO BRASILEIRO DE CIÊNCIAS DA COMUNICAÇÃO, 25., 2002, Salvador. Anais... Salvador, 2002. Disponível em : <http://galaxy. intercom.org.br:8180/dspace/bitstream/1904/18871/1/2002_NP9bortoliero.pdf>. Acesso em: 14 jan. 2011.

DELEUZE, G. Foucault. São Paulo: Brasiliense, 2006.

FOUCAULT, M. Verdade e poder. In: MACHADO, R. (Org.). Microfísica do poder. Rio de Janeiro: Graal, 2008. p.1-14.

Diálogo sobre o poder. In: MOTTA, M.B. (Org.). Estratégia, poder-saber. Rio de Janeiro: Forense Universitária, 2006a. p.253-66. (Ditos e escritos, 4).

A ética do cuidado de si como prática da liberdade. In: MOTTA, M.B. (Org.). Ética, sexualidade, política. Rio de Janeiro: Forense Universitária, 2006b. p.264-87. (Ditos e escritos, 5).

A arqueologia do saber. Rio de Janeiro: Forense Universitária, 2005a.

Michel Foucault explica seu último livro. In: MOTTA, M.B. (Org.). Arqueologia das ciências e história dos sistemas de pensamento. Rio de Janeiro: Forense Universitária, 2005b. p.145-52. (Ditos e escritos, 2).

As palavras e as imagens. In: MOTTA, M.B. (Org.). Arqueologia das ciências e história dos sistemas de pensamento. Rio de Janeiro: Forense Universitária, 2005c. p.78-81. (Ditos e escritos, 2).

A ordem do discurso. São Paulo: Loyola, 1999.

REVEL, J. Michel Foucault: conceitos essenciais. São Carlos: Claraluz, 2005.

REZENDE, L.; STRUCHINER, M. Uma proposta pedagógica para produção e utilização de materiais audiovisuais no Ensino de Ciências: análise de um vídeo sobre entomologia. Alexandria, v.2, n.1, p.45-66, 2009.

SÁ, M.B. Entre o governo dos outros e o governo de si: uma análise foucaultiana da liberdade e suas práticas em vídeos educativos do Núcleo de Tecnologia Educacional para a Saúde. No prelo. Tese (Doutorado) - Núcleo de Tecnologia Educacional para a Saúde, Universidade Federal do Rio de Janeiro, Rio de Janeiro.

SIQUEIRA, V.H.F. Tecnologia Educacional na Área da Saúde: a produção de vídeos educativos no Nutes/UFRJ. In: ASSIS, S.; VARGAS, E. P. (Orgs.). Educação, Comunicação e Tecnologia Educacional: interfaces com o campo da Saúde. Rio de Janeiro: Fiocruz, 2006. p.71-86.

O vídeo educativo produzido pelo Núcleo de Tecnologia Educacional para a Saúde-NUTES: uma visão

crítica. Rev. Bras. Educ. Med., v.22, n.2-3, p.77-82, 1998.

UFRJ/ NUTES. Catálogo de materiais instrucionais. Rio de Janeiro: NUTES/UFRJ, 1997.

XAVIER, I. Um cinema que "educa" é um cinema que nos faz pensar. Educ. Realid., v.33, n.1, p.13-20, 2008. 
Neste texto, delineamos exercício de caráter exploratório que, tomando as noções foucaultianas de acontecimento e arquivo, seleciona e analisa dois vídeos educativos produzidos pelo Núcleo de Tecnologia Educacional para a Saúde, NUTES/UFRJ -

"Coração: relações e morfologia externa" (1977) e "Hipotireoidismo na infância" (1976)

- visando indicar possíveis contribuições do referencial foucaultiano para análise desse tipo de material. No decorrer do processo analítico, acabamos nos deslocando, junto com Foucault, até seus últimos trabalhos, onde encontramos elementos que possibilitaram uma abertura para a análise de como os indivíduos, exercitando sua liberdade, podem se constituir como sujeitos políticos e éticos, na fronteira dos campos altamente disciplinares e normalizadores da educação e da saúde.

Palavras-chave: Vídeo Educativo. Análise do Discurso. Michel Foucault. Ciências da Saúde. Metodologia.

\section{Foucaultian analysis of educational videos for the Health Sciences: testing a methodology}

This paper takes the Foucauldian concepts of event (événement) and archive to make an exploratory exercise on the development of procedures to select and analyze two educational videos - "Heart: relationships and external morphology" (1977) and "Hypothyroidism in childhood" (1976) - produced at the Center of Educational Technology for Health, NUTES/UFRJ. We aimed to indicate the contribution of Foucauldian notions for the analysis of such material. In the analytical process, we have moved together with Foucault towards his late works, where we found elements that enabled an analysis of how individuals, exercising their freedom, may constitute themselves as political and ethical subjects, in the intersection of Education and Health, two highly disciplinary and normalizing fields.

Keywords: Instructional Films and Videos. Discourse Analysis. Michel Foucault. Health Sciences. Methodology.

\section{Análisis foucaultiano de vídeos educativos de Ciencias de la Salud: ensayo de una metodología}

En este texto delineamos un ejercicio de carácter exploratorio que, teniendo las nociones foucaultianas de acontecimiento y archivo, selecciona y analiza dos vídeos educativos producidos por el Centro de Tecnología Educativa en Salud, NUTES / UFRJ - "Corazón: relaciones y morfología externa" (1977) "Hipotiroidismo en la infancia "(1976) - a fin de indicar posibles contribuciones de este referente teórico para el análisis de dicho material. A lo largo del proceso analítico, terminamos en movimiento junto con Foucault hasta sus últimos trabajos, donde encontramos elementos que han permitido una apertura para el análisis de cómo los individuos, en ejercicio de su libertad, pueden constituirse en sujetos éticos y políticos en la frontera de los campos altamente disciplinarios y normalizadores de la educación y la salud.

Palabras clave: Vídeo educativo. Análisis del Discurso. Michel Foucault. Ciencias de la Salud. Metodología. 